\title{
Perception of "health" concept and environmental sustainability: a gender aspect
}

\author{
Hanna Kraievska ${ }^{1 *}$, Inna Gorofianiuk ${ }^{2}$, Liudmyla Koval $^{3}$ \\ ${ }^{1}$ Department of Ukrainian Studies, National Pirogov Memorial Medical University, Pirogova str. 56, \\ 21028 Vinnytsia, Ukraine \\ ${ }^{2}$ Ukrainian Language Department, Vinnytsia Mykhailo Kotsiubynskyi State Pedagogical \\ University, Ostrozkogo str. 32, 21001 Vinnytsia, Ukraine \\ ${ }^{3}$ Department of Ukrainian Language and Culture, Vasyl' Stus Donetsk National University, 600- \\ richchya str. 21, 21021 Vinnytsia, Ukraine
}

\begin{abstract}
The purpose of the article is to investigate the perception to human health, its preservation and the general understanding of the phenomena of vitality and health as such in the sustainable society. The article is dedicated to the gender analysis of the perception of the above phenomena. The purpose of the proposed study was to find out associations related to these concepts, to model associative fields by the men's and women's reactions, as well as to establish the most valuable features in the perception of this concept by different genders. The study used a free associative experiment in the written form. The respondents were students-leaders and their deputies (42 women and 29 men) aged 17-21. We used the statistical method to calculate the results of the experiment; as well as the comparative method and the method of modeling of associative fields. Comparing the men's and women's associative semantics of these phenomena, we conclude that there is a generally positive perception of the concept under study, but men show negative characteristics of this phenomenon slightly more than women.
\end{abstract}

\section{Introduction}

In modern sustainable society marked by the recent challenges such as globalization and global warming, and, most recently, pandemics and global diseases, the issue of forming leadership qualities of an individual in the general context of the health care system and specifically to maintain his/her own vital energy and health is extremely important $[1,2]$.

In the research literature, the leader is the one who knows and fulfills his mission, gives it priority, can persuade others to follow him. Therefore, a leader is a person who sets a goal and finds different ways and opportunities to achieve it. Is it possible to see a pattern between the level of development of leadership qualities of the individual and the attitude to his/her own health, its preservation, and in general the understanding of the phenomenon of health within the context of the environmental sustainability.

In general, human health is one of the man's greatest values which also impacts on the sustainable development of the human society. It is a prerequisite of the human energy or the

\footnotetext{
*Corresponding author: kraievsk@gmail.com
} 
vital energy of the human beings. This concept is extremely complex in social, psychological, and as a consequence - in linguistic aspects. Depending on the different socio-cultural, economic factors, speakers form their own perception of health. There may also be gender differences in the perception of the "health" phenomenon.

There are many definitions of "health" in modern literature. The most typical elements of the definition are:

1. The normal function of the organism at all levels of its organization (organs, histological, cellular and genetic structures, the normal course of physiological and biochemical processes that contribute to the individual's survival and reproduction).

2. Dynamic balance between the organism, its functions and the environment (the environmental sustainability).

3. Ability to fully fulfill basic social functions, participate in social activities and socially useful work.

4. The ability of the body to adapt to constantly changing conditions of the environment, the ability to maintain the stability of the internal environment of the organism, ensuring normal and versatile life and preservation of a living principle of the body.

5. Absence of diseases, diseased conditions, painful changes.

6. Complete physical, spiritual, mental and social well-being [3].

According to the WHO Constitution, health is not the absence of a disease or physical disabilities, but a state of complete physical, mental and social well-being; it is the natural state of the organism, which is characterized by its balance with the environment and the absence of any painful changes [4]; according to the Dictionary of the Ukrainian language, this is the state of the organism in which all its organs function normally [5].

Such definitions differ from the traditional medical model, which defines health as the absence of illness or disease and emphasizes the role of clinical diagnosis and intervention. Researchers note that the WHO definition clearly links health to well-being and conceptualizes health as a certain human right, requiring physical and social resources to reach and sustain it.

Brechmann [6] offers an information and psychological interpretation of the essence of health: "Human health is its ability to maintain age-appropriate resistance to sudden changes in the quantitative and qualitative parameters of the flow of sensor, verbal and structural information". Academician Kaznacheyev [7] emphasized that health is a holistic multidimensional dynamic state that develops in the process of realizing of the genetic potential under conditions of a specific social and ecological environment and allows a person to exercise his biological and social functions to different degrees; the process of preservation and development of physiological properties, the potential of mental and social properties; the process of maximum life expectancy at optimum efficiency and social activity. Kudriavtseva [8] defines public health as a socio-demographic category that reflects the ability of the society members to fulfill the function of further development of the society and lead a way of life that ensures the preservation, strengthening and development of this ability.

Huber et al. [9] offered a fundamentally new definition of health: "Health is the ability to adapt and self-organize, which includes the ability of people to adapt to their situation as a key to health. He also recognized the subjective element of health. In his opinion, health and well-being will depend on the needs of a specific person.

Thus, the concept under study is complex and multidimensional. As you can see, scientists interpret the studied concept differently. According to Boichuk [10] there are more than 450 definitions of the concept of "health" that have been formulated by experts of various scientific disciplines. The scientist pointed out six basic types of essential elements 
of the health definition:

1. Health as a norm of functioning of an organism at all levels of its organization;

2. Health as a dynamic balance (harmony) of vital functions of an organism;

3. Health as a full-fledged fulfillment of basic social functions, participation in society and active labor activity;

4. The body's ability to adapt to changing environmental conditions;

5. Absence of pathological changes and normal state of health;

6. Complete physical, spiritual, mental and social well-being.

As we can see, the problem of perception of the health phenomenon is controversial. Representatives of biomedical sciences mainly deal with this issue. However, integration processes in science have led to the fact that various aspects of the perception of human "health" are also of scientific interest in pedagogy, psychology, philosophy and sociology. The concept of "health" in the linguistic aspect has repeatedly become the object of study of linguists: they analyzed different planes of the concept of "health" in the Ukrainian linguistic picture of the world; evaluation and emotional specificity of the nomen; phraseological units for the designation of the human health; the phenomenon of "health" in age and national aspects.

Our research is, to a certain extent, a continuation of the studies on "Health as a conceptual phenomenon: age, national and social aspects of the associative semantics" [11]. The results of the mentioned work showed that representatives of different linguistic cultures of the same age have more common ideas about the health phenomenon than native speakers of Ukrainian linguistic culture of different ages. Health is a cross-cultural phenomenon, so age, not nationality, is a dominant factor in the formation of perceptions of health [11]. In our opinion, it is important to continue to study the phenomenon of health in the gender aspect of analysis.

Therefore, in the proposed study, we will attempt to find out certain motives, assessments, attractions, personality settings that appear in the respondent's mind when perceiving the concept of "health". To describe ways of conceptualization of the "health" concept by representatives of different articles, compare models of implementation of the "health" concept. The results of the study show us the interpretation of the health phenomenon in general.

The relevance of our study is strengthened by the fact that the word "health" is absent in the Associative Dictionaries of the Ukrainian Language $[12,13]$ and the Slavic Associative Dictionary [14]. This token is neither represented in the first associative dictionary published in 1910 in the USA [15]. The list of the word associations of this dictionary formed the basis for a number of subsequent works. The analyzed token is present as a word-stimulus in the Dictionary of Associative Norms of the Turkish Language [16] and the Edinburgh Associative Dictionary [17].

Such a study should be considered interdisciplinary, since the problem of society stratification through the interaction of language and gender is raised, and the medicalbiological concept is taken for analysis.

The scientific novelty is that, for the first time, the results of a free associative experiment aimed at explaining the perception of health by Ukrainian youth were put into practice, an attempt was made to identify a common and different perception of the phenomenon of health by women and men. The object of the study is the conceptualization of the concept of health by representatives of different articles. The subject of the analysis is the linguistic realization of the concept of health as a basis for the linguistic modeling of ideas about the state of the human body. The hypothesis of the study is the assumption of a difference in the perception of the phenomenon of "health" by representatives of the same social group, the same age, but different sexes. 


\section{Research objectives}

The objective of the study is to find out by means of a free associative experiment what students-leaders of different sexes associate with health; to compare the men's and women's results; to model associative fields by men's and women's reactions; to establish what is the most valuable in the perception of this concept by different sexes.

\section{Research methods and methodology}

A free associative experiment was used during the study. For the first time an associative experiment was applied in psychology. The purpose of such an experiment is to identify associations that an individual has formed over the life experience.

There are 3 types of associative experiment: free, purposeful and chain.

We used a free associative experiment, during which respondents were offered a word (word-stimulus) to which they had to react with a word (word-reaction), to which no requirements for form, content, manner of expression was imposed.

Preference was given to the written form avoiding collective responses, emotional cues, exclamations.

Thus, the respondents were offered a "health" word-stimulus, which they had to respond as quickly as possible whatever came uppermost. Age and gender should also be specified. 42 women and 29 men were interviewed.

The material of the study was the results of a free associative experiment conducted with 69 leaders of student groups and their deputies of the Faculty of Economics at Vasyl Stus Donetsk National University. In our study, the following factors were set:

1. Social group - students-leaders;

2. Specialty - economics;

3. The number of word-stimulus offered - one word-stimulus "health";

4. Nationality - Ukrainians;

5. Country of residence - Ukraine;

6. Age of the respondents - 17-21 years;

7. Mother tongue - Ukrainian. Variable factors included the sex of the respondents.

The results of this experiment can be considered as a certain associative profile of consciousness images, which combine the mental and sensory components of the health perception by respondents of different sexes.

We used the statistical method to calculate the results of the experiment; as well as the comparative method and the method of modeling of associative fields.

The statistical method was used to calculate the frequency of the same reactions to the word-stimulus "health" and the percentage ration. In Table 1 and Table 2, for each wordreaction, the number of respondents who answered equally is given in parentheses.

The comparative method was used to compare the results of the associative experiment in a group of students of male and female genders.

The associative field modeling method is aimed at distribution of the reactions obtained to the nucleus, the near periphery as an intermediate link, and the periphery. The boundary between the nucleus and the peripheral reactions is calculated by the formula $n / 2$, where $n$ is the upper frequency limit of a specific response to a word-stimulus [18]. For example, in our study, the most frequent women's reaction is the word sports -9 reactions, then the reaction with a frequency of at least 4,5 will go to the nucleus. Other reactions are distributed between the near periphery and the periphery according to this principle. 


\section{Main results}

We received 81 associations. This is more than the total number of respondents, as men in 6 cases gave 2 or more word-reactions. In this case, only the first word-reaction was considered and reported in the study.

There were no denials in women's questionnaires. Respondents clearly followed the instructions, mentioning one word-association (Table 1).

Table 1. The structure of the semantic field of the "health" token according to the results of a free associative experiment - female.

\begin{tabular}{|c|c|c|}
\hline $\begin{array}{c}\text { The nucleus of the } \\
\text { associative field }\end{array}$ & $\begin{array}{c}\text { The near periphery of the } \\
\text { associative field }\end{array}$ & $\begin{array}{c}\text { The periphery of the } \\
\text { associative field }\end{array}$ \\
\hline $21,5 \%$ & $35,7 \%$ & $42,8 \%$ \\
\hline Sports (9) & $\begin{array}{c}\text { Happiness (4), sleep (4), body } \\
\text { condition (3), healthy lifestyle (4) }\end{array}$ & $\begin{array}{c}\text { Well-being (2), peace (2), } \\
\text { wealth (2), hospital (2), pills } \\
(2), \text { life (2), immunity, dream, } \\
\text { treasure, joy, power, smile }\end{array}$ \\
\hline
\end{tabular}

The recorded associations have mostly positive and neutral semantics, although there have been 4 negative reactions (hospital (2), pills (2)). All words-reaction are grouped into semantic groups.

The first group includes a number of words related to the factors of health preservation: healthy lifestyle, sports, sleep, rest, immunity.

The second group is filled with reactions that indicate the images that the woman associates with health: smile, dream, joy, treasure, wealth, well-being, strength, happiness.

The third group consists of reactions related to the medical sphere: hospital, pills.

The fourth group is represented by the phrase body condition and is an element of the essence of the concept of health. The ratio of the quantitative composition of semantic groups (by the results of the associative experiment among women): the associative field is a set of reactions to the word "stimulus" (detected experimentally) represents a specific model that captures the associative bonds of words. The word "stimulus" is the one given to the respondent which she or he must quickly respond to with another word. The word "reaction" is a word association that arises in a given person's memory and is caused by the offered stimulus word.

Table 2. The structure of the semantic field of the "health" token according to the results of a free associative experiment - men

\begin{tabular}{|c|c|c|}
\hline $\begin{array}{c}\text { The nucleus of the } \\
\text { associative field }\end{array}$ & $\begin{array}{c}\text { The near periphery of the } \\
\text { associative field }\end{array}$ & $\begin{array}{c}\text { The periphery of the } \\
\text { associative field }\end{array}$ \\
\hline $38 \%$ & $27,5 \%$ & $34,5 \%$ \\
\hline $\begin{array}{c}\text { Healthy lifestyle (5), } \\
\text { strength (3), pills (3) }\end{array}$ & $\begin{array}{c}\text { Food (2), pharmacy (2), } \\
\text { hospital (2), life (2) }\end{array}$ & $\begin{array}{c}\text { No bad habits, sports, } \\
\text { work, body condition, } \\
\text { happiness, good thoughts, } \\
\text { expensive, smile; something } \\
\text { that is easy to lose and hard } \\
\text { to regain; } \odot \text {. }\end{array}$ \\
\hline
\end{tabular}


The largest group includes the reactions of women, related to factors, conditions of health preservation $(50 \%)$, which are associated with an active and right way of life. All the images (32\%) that women associate with health are bright and life-affirming. Reactions show a mostly positive image of health as the highest value of an individual.

Analysis of the results of the experiment with men showed that in 6 cases they provided the whole associative series for the word-stimulus. Under such conditions, the first reaction was taken into account. No questionnaire refusals were recorded (see Table 2 above).

The overall image of the men's associative semantics of "health" is mostly positive, but it is not devoid of neutral and somewhat negative characteristics. All tokens are grouped into 6 semantic groups (see Figure 1).

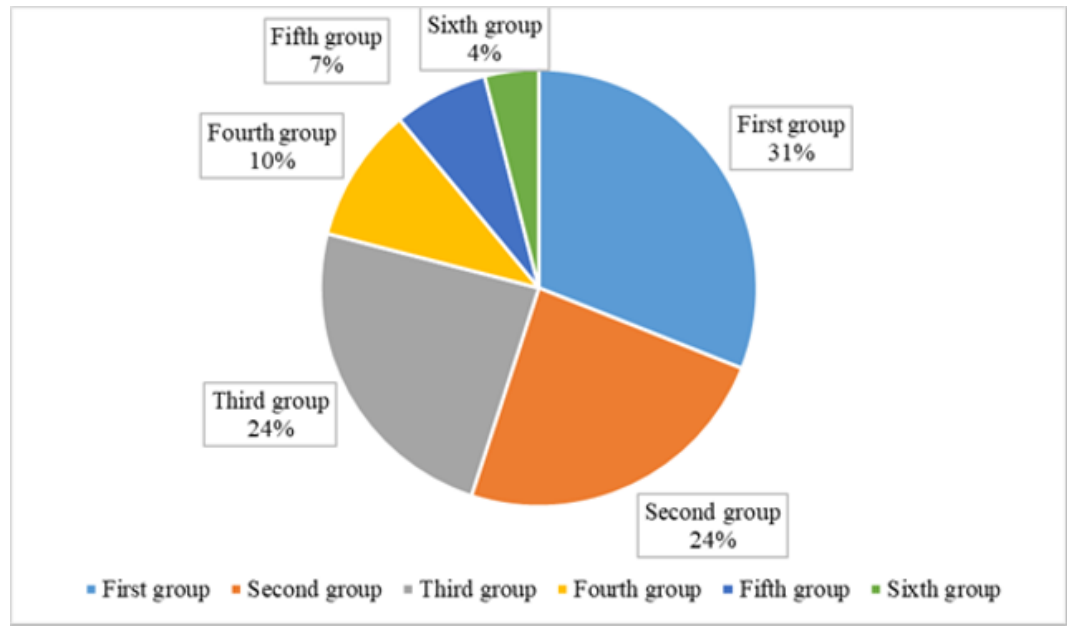

Fig. 1. Ratio of the quantitative composition of semantic groups (by the results of the associative experiment among men)

Among the male respondents, the largest group of reactions related to physical activity, refusal from bad habits and nutrition (50\%). In the men's minds the word-stimulus "health" is equally (24\% each) related to medical concepts and certain images with which it is associated. The frequency responses related to the evaluation, characteristics of health properties, the essence of the concept and there is a single reaction symbol. Men's associative semantics of health is overwhelmingly positive, but men demonstrate negative characteristics of this phenomenon (hospital, pharmacy, pills; something that is easy to lose and hard to regain) more than women.

\section{Discussion}

The comparison of the associative fields, modeled by the men's and women's wordsreactions, shows that in both cases according to the number of reactions the factors of health preservation dominate. The reaction-images with which a person associates health prevail by variety: women -8 tokens, men -6 . Several reactions represent the essence of the concept in both groups of respondents. Also typical for both groups of respondents is the reactionabbreviation $30 \%$ (in Ukrainian) healthy lifestyle.

Unlike women, men have reactions to evaluation, characteristics of health properties. The symbol (-) was recorded without a verbal explanation, which is more common of women, and there was an idiom with obscene words, which can be considered as a certain 
manifestation of men's linguistic aggression.

In the nuclei of both associative fields there are reactions related to the factors of health preservation, but the men's nucleus ( 4 tokens) is more diverse than women's ( 1 token). The nuclear features of the field, modeled by the results of the men's reactions, come to the near periphery and the women's periphery.

Analyzing the set of reactions of the near periphery of both groups of respondents, we note that the medical motives dominate in the men's group and factors associated with an active and right way of life prevail by women.

The filling of the periphery of the associative fields differs significantly. Only the smile reaction was common.

In general, the composition of the considered associative fields reveals certain coincidences (smile, pills, hospital, strength, healthy lifestyle, sports, body condition, happiness), differing mainly only in their structure, i.e. the position in the men's and women's value hierarchy. Most of the common associations are nuclear signs or belong to the near periphery. It has also been observed that the word associations (no bad habits, body condition, good thoughts; something that is easy to lose and hard to regain) prevail more in men's associations than in women's (body condition).

Some coincidences with the results of our study are found in the materials of the Dictionary of Associative Norms of the Turkish Language. The experiment was conducted with students and teachers of the Erciyes University aged 17-25 years (Kayseri) in 20042005. No gender distinction was made in the mentioned work. There is a reaction of sports, which dominates in the valuable hierarchy of the Ukrainian youth of female gender, is also numerous and belongs to the nuclear reactions. However, the nuclear words-reactions of men healthy lifestyle, strength, pills are not recorded as a response to a "health" word-stimulus. Such results prove the partial similarity of the perception of such a universal concept (known to all mankind and represented in different languages) by the youth of different cultures. However, this still confirms the presence of associative universals in youth of different cultures $[19,20]$.

In the example of the Edinburgh Associative Dictionary that was give earlier, the reactions that are not specified by our respondents are represented as frequency responses. The matches are only traced in the periphery and the near periphery.

According to the results of the association's research, young respondents generally do not correlate health with the traditional medical model, which defines health as the absence of illness or disease and emphasizes the role of a clinical diagnosis and intervention. Most of the surveyed students recognize health as an active way of life, sports. Although the research in the senior age group showed the person's physiological feeling when nothing hurts as a nuclear reaction. $15 \%$ of the senior and elderly people associated this concept alike. The comparison of the reactions of students of different sexes and the senior and elderly shows that the age is a dominant factor compared to the gender in the formation of the health perception.

\section{Conclusions}

The gender analysis of the associative field of the "health" concept revealed common and specific in the minds of the students-leaders. By comparing the men's and women's associations it was found that the factors of health preservation were valuable for both groups. Sports and healthy lifestyle were the most frequent responses. This is probably due to the promotion of an active and healthy lifestyle, a certain fashion for it. Common reactions of men are associations, with reference to the medical topics, and women have certain images that correlate with the health. In general, the concepts that youth associate with the health are positive. The conducted study has revealed the peculiarities of the 
students' world view, attitude to the health as the highest value of an individual.

The associative field is a set of reactions to the word-stimulus detected experimentally; a specific model that captures the associative bonds of words. The wordstimulus is a word given to the respondent, which he or she must quickly respond to in another word. The word-reaction is a word association that arises in a person's memory, caused by the offered word-stimulus.

In the course of this study, we obtained 81 associations were obtained for the "health" word-stimulus. A number of specific features of perception of the "health" phenomenon by representatives of different sexes were established. The associative fields of two sexes were modeled according to the obtained associations. The composition of the considered associative fields reveals certain coincidences, but differs in its structure, i.e. the position in the men's and women's value hierarchy. In the nucleus of both fields there are reactions related to the factors of health preservation. Medical motives dominate in the men's near periphery, while women specified the motives connected with the active and healthy lifestyle. There are virtually no matches in the far periphery of the associative fields.

This study does not claim to be exhaustive. In perspective we plan to expand the experimental base and improve the methods of conducting and processing of the results of the experiment, which will allow to form a certain social portrait of the student in the context of perception of the health.

\section{References}

1. C. Guerriero, A. Haines, M. Pagano, Nature Sustainability, 3(7), 494-496 (2020)

2. A. Khayatzadeh-Mahani, R. Labonté, A. Ruckert, E. De Leeuw, Global health promotion, 26(1), 100-104 (2019)

3. O.A. Fedko, http://www.dy.nayka.com.ua/?op=1\&z=76 (2009)

4. WHO, www.who.int/governanceleb/who_constitution_en.pdf (1946)

5. SUM Slovnyk ukrainskoi movy (1972)

6. Y.Y. Brechmann, Vvedenye v valeolohyiu-nauku o zdorove. Fizkultura i sport (1990)

7. V.P. Kaznacheyev, Teoretycheskye osnovy valeolohii: Fundamentalnye nauky (1993)

8. E.N. Kudriavtseva, Voprosy filosofii, 12, 98-109 (1987)

9. M. Huber, J.A. Knottnerus, L. Green, British Medical Journal, 343(2), 3-4 (2011)

10. Y.D. Boichuk, Zahalna teoriia zdorovia ta zdoroviazberezhennia (2017)

11. H.P. Kraievska, I.V. Gorofianiuk, Health as a conceptual phenomenon: age, national and social aspects of the associative semantics (2020)

12. N.P. Butenko, Slovnyk asotsiatyvnykh norm ukrainskoi movy (1979)

13. S.V. Martinek, Ukrainskyi asotsiatyvnyi slovnyk: Vid sty 'mulu do reakciyi (2007)

14. (SAS) Slavianskii assotsyatyvnyi slovar: russkii, belorusskii, bolharskii, ukraynskii (2004)

15. G.H. Kent, A.J. Rosanoff, Americal Journal of Insanity, 67, 37-97 (1910)

16. (TDCNS) Türk Dili Çă̆rışım Normları Sözlüğü: 160000 çă̆rışım (2014)

17. G.R. Kiss, G. Armstrong, R. Milroy, http://www.eat.rl.ac.uk/(1972)

18. A.P. Klymenko, Voprosy psykholinhvisticheskoho yzuchenia semantiki (1970)

19. B. Wheaton, G. Roy, R. Olive, Sustainability, 9(12), 2298 (2017)

20. H. Kruize, N. Van der Vliet, B. Staatsen, R. Bell, A. Chiabai, G. Muiños, S. Quiroga, P. Martinez-Juarez, M. Aberg Yngwe, F. Tsichlas, P. Karnaki, M. Lima, S. García de Jalón, M. Khan, G. Morris, I. Stegeman, International Journal of Environmental Research and Public Health, 16(22), 4403 (2019) 